\title{
CORRECTION
}

View Article Online

View Journal | View Issue
W) Check for updates

Cite this: J. Anal. At. Spectrom., 2020, 35, 1496

DOI: $10.1039 / d 0 j a 90047 h$

rsc.li/jaas

\section{Correction: Micro-destructive analysis with high sensitivity using double-pulse resonant laser- induced breakdown spectroscopy}

\author{
Zhiyang Tang, ${ }^{a}$ Ran Zhou, ${ }^{a}$ Zhongqi Hao, ${ }^{* a}$ Shixiang Ma, ${ }^{a}$ Wen Zhang, ${ }^{a}$ Kun Liu, ${ }^{a}$ \\ Xiangyou $\mathrm{Li}^{a}{ }^{a}$ Xiaoyan Zeng ${ }^{\mathrm{a}}$ and Yongfeng $\mathrm{Lu}^{\mathrm{b}}$ \\ Correction for 'Micro-destructive analysis with high sensitivity using double-pulse resonant laser-induced \\ breakdown spectroscopy' by Zhiyang Tang et al., J. Anal. At. Spectrom., 2019, 34, 1198-1204, DOI: \\ 10.1039/C9JA00072K.
}

The authors regret an error in the affiliation of one of the authors, Yongfeng $\mathrm{Lu}$, in the original manuscript. The correct affiliation is: University of Nebraska-Lincoln (UNL) and not Wuhan National Laboratory for Optoelectronics (WNLO) at the Huazhong University of Science and Technology (HUST). The corrected list of authors and affiliations for this paper is as shown above.

The Royal Society of Chemistry apologises for these errors and any consequent inconvenience to authors and readers. 